\title{
Postoperative analgesia with "3-in-1" femoral nerve block after prosthetic hip surgery
}

\author{
Roxane Fournier MD, \\ Elisabeth Van Gessel MD, \\ Giovanni Gaggero MD, \\ Silvère Boccovi $\mathrm{MD}$, \\ Alain Forster MD, \\ Zdravko Gamulin MD
}

Purpose: To evaluate the efficacy of a single shot " 3 -in-I" femoral nerve block for prosthetic hip surgery in association with general anaesthesia on post-operative analgesia.

Methods: Forty patients, ASA I to 3, received sham block or "3-in-1" femoral nerve block, following Winnie's landmarks with a nerve stimulator, and $40 \mathrm{ml}$ bupivacaine $0.5 \%$ with epinephrine were injected after induction of anaesthesia. Vecuronium, $0.1 \mathrm{mg} \cdot \mathrm{kg}^{-1}$, was added after performing the block and anaesthesia was maintained with isoflurane, oxygen $40 \%$ and nitrous oxide $60 \%$. Fentanyl, $1.5 \mu \mathrm{g} \cdot \mathrm{kg}^{-1}$, was administered before incision to all patients. Heart rate, blood pressure, fentanyl requirements and $F_{E T}$ iso were measured throughout surgery. During the post-operative period, $75 \mathrm{mg}$ diclofenac im and/or $0.1 \mathrm{mg} \cdot \mathrm{kg}^{-1}$ morphine sc were administered when pain score was $>3 / 10$ and repeated when necessary. Pain scores at first analgesic intervention, at $24 \mathrm{hr}$ and 48 $\mathrm{hr}$ as well as diclofenac and morphine requirements after surgery were recorded.

Results: There was no difference in anaesthetic requirements during surgery. The time from performance of sham or " 3 -in-।" femoral nerve block to the first analgesic intervention ( $261 \pm 49$ min versus $492 \pm 40$ min, $P<0.05)$ and time from extubation to the first analgesic intervention $(61 \pm 44 \mathrm{~min}$ vs $298 \pm 39 \mathrm{~min}, P<0.05)$ were prolonged in the study group. However, pain scores and the analgesic requirements in the postoperative periods ( 24 and $48 \mathrm{hr}$ ) were similar.

Conclusion: There is a short-term benefit during the first few postoperative hours in.using a single shot "3-in-I" femoral nerve block to complement general anaesthesia for elective hip surgery.

Objectif : Évaluer l'efficacité du bloc fémoral «3-dans-1 » en une injection pour la chirurgie prosthétique de la hanche associé à une anesthésie générale pour procurer l'analgésie postopératoire.

Méthodes : Quarante patients, ASA I à 3, ont reçu un bloc factice ou un bloc fémoral «3-dans- I " avec repérage des points de Winnie par stimulateur nerveux et réalisé avec de la bupivacaïne $0,5 \%$ adrénalinée $40 \mathrm{ml}$ injectée après l'induction de l'anesthésie. Du vécuronium, $0,1 \mathrm{mg} \cdot \mathrm{kg}^{-1}$, était ajouté après la réalisation du bloc et d'une anesthésie maintenue à l'isoflurane, oxygène $40 \%$ et protoxyde d'azote $60 \%$. On administrait I,5 $\mu \mathrm{gg}^{\mathrm{kg}} \mathrm{g}^{-1}$ de fentanyl à tous les patients avant l'incision. La fréquence cardiaque, la pression artérielle, les besoins en fentanyl et la $\mathrm{P}_{\mathrm{ET}}$ iso étaient mesurés pendant la chirurgie. À la période postopératoire, les patients recevaient $75 \mathrm{mg}$ de diclofénac im et/ou $0,1 \mathrm{mg} \cdot \mathrm{kg}^{-1}$ de morphine sc lorsque le score dépassait 3 sur l'échelle de 10 , au besoin. On enregistrait les scores de douleurs au moment de la première administration d'analgésique, à $24 \mathrm{~h}$ et $48 \mathrm{~h}$ de même que les doses de diclofénac et de morphine après la chirurgie.

Résultats : Les besoins d'anesthésie étaient les mêmes pendant la chirurgie. L'intervalle entre le bloc factice ou le bloc «3-dans- 1 » et la première administration d'analgésique $(261 \pm 49 \min$ vs $492 \pm 40 \mathrm{~min}, P<0,05)$ et l'intervalle entre l'extubation et la première administration analgésique (61 \pm 44 min vs $298 \pm 39 \min , P<0,05)$ se prolongeaient dans le groupe d'étude. Cependant, les scores de douleur et les besoins analgésiques de la période postopératoire (à 24 et $48 \mathrm{~h}$ ) étaient semblables.

Conclusion : Le bloc fémoral en une injection «3-dans-l» administré comme complément à l'anesthésie générale procure un avantage à court terme au cours des premières heures qui suivent une intervention chirurgicale non urgente de la hanche.

From the Department of Anaesthesiology, University Hospital of Geneva, 1211 Genève 14, Switzerland. Address correspondence to: Dr. R. Fournier. Accepted for publication October 23, 1997. 
$\mathrm{T}$ HE "3-in-1" femoral nerve block, described by Winnie, ${ }^{1}$ through a single injection of a sufficient volume of local anaesthetic just below the inguinal ligament blocks the lum-

bar plexus. This occurs through cephalad movement of the local anaesthetic via a fascial conduit containing the femoral, lateral cutaneous, and obturator nerves, and is enhanced by compression applied distal to the site of injection with the needle angled proximally.

This type of block is easy to perform and is commonly used for $\mathrm{knee}^{2-7}$ and fractured femur shaft surgery. ${ }^{8,9}$ It provides good post-operative analgesia and reduces post-operative analgesic requirements, specially if a continuous technique is performed. ${ }^{4,5}$ On the contrary, the results of studies, investigating the efficacy of "3-in-1" nerve block for hip surgery are incomplete and inconclusive. ${ }^{10,11}$ The aim of this study was to evaluate the efficacy of a single shot " 3 -in-1" femoral nerve block on post-operative analgesia after total hip replacement.

\section{Patients and methods}

After institutional approval, informed consent was obtained from 40 patients, ASA 1 to 3 , scheduled for total hip replacement under general anaesthesia. All were premedicated with $7.5 \mathrm{mg}$ midazolam po $60 \mathrm{~min}$ before the scheduled operating time.

Patients were randomly assigned to two groups:

- group 1: general anaesthesia (GA) and sham block; $\mathrm{n}=\mathbf{2 0}$

- group 2: general anaesthesia with a "3-in-1" femoral nerve block (GA+FNB) performed just after induction of anaesthesia; $n=20$.

After arrival in the operating room, patients were monitored continuously using an ECG and pulse oximeter, and arterial blood pressure was measured with an automatic non-invasive device. A 17-gauge needle was inserted in the forearm and a crystalloid infusion started.

General anaesthesia was induced with $5-7 \mathrm{mg} \cdot \mathrm{kg}^{-1}$ thiopentone, and $1.5 \mu \mathrm{g} \cdot \mathrm{kg}^{-1}$ fentanyl. Before the administration of $0.1 \mathrm{mg} \cdot \mathrm{kg}^{-1}$ vecuronium, a second anaesthetist not in charge of the patient, and in the absence of the anaesthetist responsible of the investigation, performed a simple needle puncture at the site of the femoral nerve in the patients of group GA and a femoral nerve block following Winnie's landmarks in patients of group GA + FNB. The femoral nerve was localised with a nerve stimulator. Forty millilitres of bupivacaine $0.5 \%$ with epinephrine 1:200000 were injected when quadriceps contraction with an output of $0.4 \mathrm{~mA}$ or less was obtained, through a 22 -gauge, $6 \mathrm{~cm}$ needle angled proximally to assist spread.
Anaesthesia was maintained with isoflurane, and a mixture of oxygen $40 \%$ and nitrous oxide $60 \%$. In all patients $1.5 \mu \mathrm{g} \cdot \mathrm{kg}^{-1}$ fentanyl were added before the surgical incision (about $30 \mathrm{~min}$ after performing the real or sham block). Supplemental fentanyl at the same dose was administrated only if the pulse rate and/or the mean arterial pressure rose $30 \%$ above resting values, with a maximum end expiratory isoflurane concentration of $1 \%$.

In the recovery room, the pain score was assessed using visual analogue scale (VAS), from 0 to 10 (0 meaning no pain at all and 10 an unbearable pain) and was recorded. If the VAS exceeded $3 / 10$ at any time, $75 \mathrm{mg}$ diclofenac $i m$ were administered by nurses in charge; if necessary, $30 \mathrm{~min}$ later, $0.1 \mathrm{mg} \cdot \mathrm{kg}^{-1}$ morphine $s c$ was added. Both of these drugs could be repeated in the recovery room. Patients were authorised to leave the recovery room if their VAS was $<4 / 10$. On the surgical ward, the same criteria were applied to choose the analgesic.

Variables recorded every five minutes during surgery included : mean arterial pressure (MAP), end expiratory isoflurane concentration, and supplemental fentanyl requirements. During the postoperative period, the following variables were noted: time from sham block or "3-in- 1 " femoral nerve block performance to first analgesic requirement, time from extubation to the first analgesic requirement, pain scores before first analgesic intervention and at $24 \mathrm{hr}$ and $48 \mathrm{hr}$, the total number of analgesic interventions per patient over $24 \mathrm{hr}$ and 48 $\mathrm{hr}$ as well as the total dose of diclofenac and morphine per patient at the same times.

Side effects of the " 3 -in-1" femoral nerve block such as haematoma, hypoaesthesia for $>24$ hours or signs of infection at the puncture site were recorded.

Data are presented as mean $\pm S D$ or median and range. Statistical analyses were performed using unpaired t test, Mann Whitney- $U$ or Chi square as required. A $P$ value $<0.05$ was considered significant.

\section{Results}

Patients in both groups were comparable in age, weight, sex distribution and ASA physical status (Table I).

TABLE I Patients characteristics.

\begin{tabular}{lll}
\hline & $G A$ & $G A+F N B$ \\
\hline Age (yr) & $71 \pm 9$ & $68 \pm 12$ \\
Weight $(\mathrm{kg})$ & $71 \pm 12$ & $71 \pm 17$ \\
Female/male & $11 / 9$ & $16 / 4$ \\
ASA status I/II/III & $2 / 16 / 2$ & $7 / 9 / 4$ \\
\hline
\end{tabular}

Mean $\pm S D, n=20$ in each group. $G A$ : general anaesthesia and sham block; GA + FNB : general anaesthesia and "3-in-1" femoral nerve block. 


\section{Peroperative data}

No differences in the duration of surgery or supplemental fentanyl requirements were found during operation (Table II). Only three patients needed a dose of supplemental fentanyl, one in the GA group and two in the GA+ FNB group. The end expiratory isoflurane concentration achieved and mean arterial pressure changes were comparable in the groups (Figure 1,2).

TABLE II Peroperative data.

\begin{tabular}{lll}
\hline & $G A$ & $G A+F N B$ \\
\hline Fentanyl $(\mu \mathrm{g})$ & $235 \pm 50$ & $235 \pm 62$ \\
Duration of surgery $(\mathrm{min})$ & $150 \pm 41$ & $140 \pm 32$ \\
\hline
\end{tabular}

Mean $\pm S D, n=20$ in each group. GA: general anaesthesia and sham block; GA + FNB : general anaesthesia and "3-in-1" femoral nerve block.

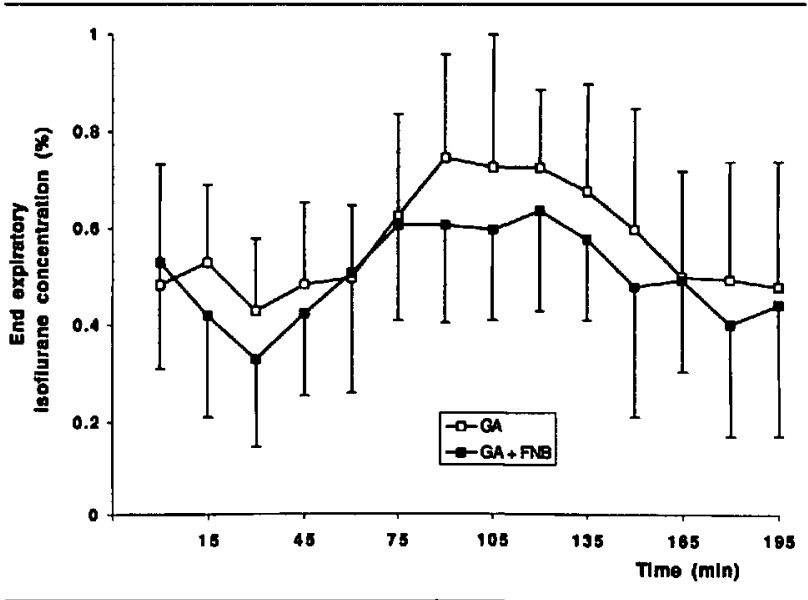

FIGURE 1 End expiratory isoflurane concentration (\%) for the GA group (general anaesthesia) and the GA + FNB group (general anaesthesia with a " 3 -in-1" femoral nerve block) during surgery.

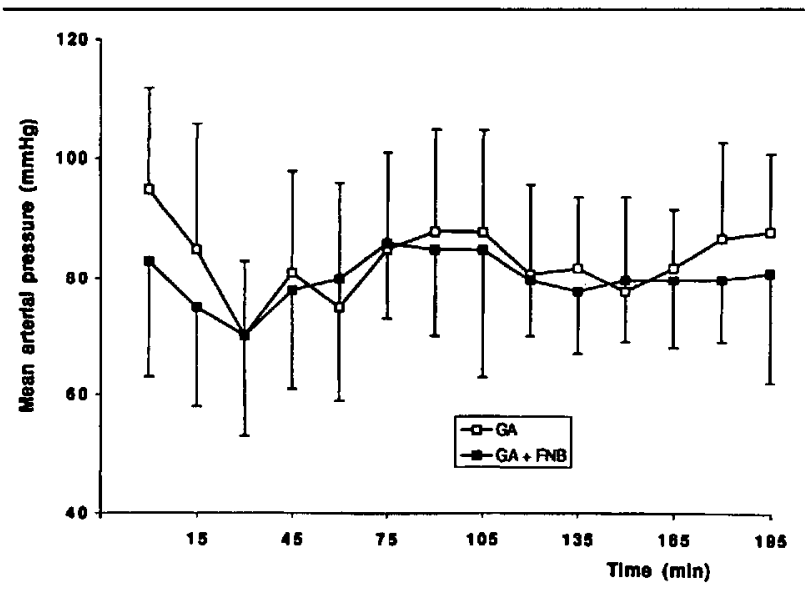

FIGURE 2 Mean arterial pressure for the GA group (general anaesthesia) and the GA + FNB group (general anaesthesia with a " 3 -in-1" femoral nerve block) during surgery.

\section{Postoperative data}

The times from sham block or " 3 -in-1" femoral nerve block performance to first analgesic requirement, and from extubation to the first analgesic requirement were longer in group GA + FNB $(P<0.05)$ than in the GA group. However, no difference in analgesic requirements of morphine and diclofenac, or in the total number of analgesic interventions per patient were found. Pain scores recorded at first analgesic intervention and at the $24 \mathrm{hr}$ show no differences between the two groups (Table III).

On the second post-operative day, six patients of group GA and three patients in group GA + FNB received ibuprofen prescribed by the surgeon and were excluded from further data analyses (Table IV). During the second postoperative day, analgesic requirements, total number of analgesic interventions and pain scores were also comparable between groups.

No side effects such as paresthesiae or dysesthesiae in the area covered by the block, haematoma or signs of infection were observed.

TABLE III Postoperative variables during the first $24 \mathrm{hr}$.

\begin{tabular}{lll}
\hline & $G A$ & $G A+F N B$ \\
\hline $\begin{array}{l}\text { Time from extubation to lst } \\
\text { analgesic intervention (min) }\end{array}$ & $61 \pm 44$ & $298 \pm 39^{*}$ \\
$\begin{array}{l}\text { Time from sham/real block to lst } \\
\text { analgesic intervention (min) }\end{array}$ & $261 \pm 49$ & $492 \pm 40^{*}$ \\
$\begin{array}{l}\text { Pain score at first analgesic } \\
\text { intervention }\end{array}$ & $7(4-10)$ & $7(4-9)$ \\
$\begin{array}{l}\text { Pain score at } 24 \mathrm{hr} \\
\text { Morphine 0-24 hr (mg) }\end{array}$ & $2(0-5)$ & $2(0-6)$ \\
$\begin{array}{l}\text { Diclofenac 0-24 hr (mg) } \\
\text { Number of analgesic interventions } \\
\text { at } 24 \mathrm{hr}\end{array}$ & $101 \pm 50$ & $85 \pm 57$ \\
\hline
\end{tabular}

Mean $\pm S D$ or median with ranges in parenthesis, $n=20$ in each group. GA: general anaesthesia and sham block; GA + FNB: general anaesthesia and "3-in-1" femoral nerve block. " $P<0.05$.

TABLE IV Postoperative variables during the second day

\begin{tabular}{lll}
\hline & $G A$ & $G A+F N B$ \\
& $n=14$ & $n=17$ \\
\hline Pain score at $48 \mathrm{hr}$ & $0(0-4)$ & $2(0-4)$ \\
Morphine 24-48 hr (mg) & $5 \pm 7$ & $4.6 \pm 5$ \\
$\begin{array}{l}\text { Diclofenac 24-48 hr (mg) } \\
\text { Number of analgesic }\end{array}$ & $59 \pm 74$ & $56 \pm 68$ \\
interventions 24-48 hr & $1.5 \pm 0.9$ & $1.7 \pm 1.4$ \\
\hline
\end{tabular}

Mean \pm SD or median with ranges in parenthesis. GA: general anaesthesia and sham block; GA + FNB: general anaesthesia and "3-in-1" femoral nerve block. ${ }^{*} P<0.05$. 


\section{Discussion}

The results of the present study indicate that a "3-in-1" femoral nerve block performed in association with general anaesthesia for total hip replacement improves analgesia for a short period of four to five hours after the operation, but does not reduce perioperative and post-operative analgesic requirements.

We performed the " 3 -in-1" femoral nerve block just after induction of general anaesthesia; thus, the maximal extent of block could not be tested. Nevertheless, we used the standard nerve stimulation technique (muscular response with output of $0.4 \mathrm{~mA}$ or less) and a large volume of local anaesthetic $(40 \mathrm{ml})$ was administered, which should provide an optimal " 3 -in-1" femoral nerve block in the majority of patients.

During surgery, no opioid-sparing effect was seen. Supplemental fentanyl requirements as well as end expiratory isoflurane concentrations and haemodynamic variables were comparable in both groups. This could be explained by the methodology used. All patients received $1.5 \mu \mathrm{g} \cdot \mathrm{kg}^{-1}$ fentanyl at induction of anaesthesia and the same dose was administered just before the surgical incision. Although $3 \mu \mathrm{g} \cdot \mathrm{kg}^{-1}$ of fentanyl is not a high dose, considering the extent of this surgical procedure, it could have prevented an opioid-sparing effect. However, heart rate and blood pressure are not the most reliable variables of peroperative patient discomfort.

During the post-operative period, the " 3 -in- 1 " femoral nerve block delayed the time to the first analgesic intervention. Patients in the control group needed an analgesic $61 \pm 44$ min after the end of surgery whereas patients from the study group required analgesia only five hours after the surgical procedure. This allowed for better patient comfort in the early postoperative period. Most patients from the study group received their first analgesic medication on the ward. Pain scores of patients in both groups were surprisingly high (7 (4-9) and $7(4-10))$ although they were told to ask for analgesic intervention with a score of $3 / 10$. This points out the difficulty of communication between patients and nursing staff.

No reduction in postoperative analgesia requirements was shown over 24 or $48 \mathrm{hr}$. These findings suggest that performing a "3-in-1" femoral nerve block at the end of the surgery would have been more beneficial.

In theory, femoral nerve block performed with $200 \mathrm{mg}$ bupivacaine should last longer than $500 \mathrm{~min}$. Anatomically, the incision may encroach sacral and $T_{12}$ roots, which are not blocked by the inguinal paravascular technique. Many authors have questioned Winnie's hypothesis of a fascia. ${ }^{12-14}$ Parkinson ${ }^{12}$ has demonstrated, by measuring the extent of motor and sensory blockade (testing motor function or pin-prick response) that the anterior approach of Winnie using paraesthesia or nerve stimulation is effective in producing femoral and lateral cutaneous nerve blocks, but ineffective for an obturator block. Though the obturator nerve is mainly a motor nerve, it also provides some sensory distribution to the hip. In addition, the hip is innervated by some branches arising form the sciatic nerve. These facts could explain the shorter period of analgesia than expected observed in our study.

Very few studies have examined the analgesic effects of a "3-in-1" femoral nerve block during hip surgery: ${ }^{10,11}$ they are published in an abstract form, and they concern a continuous " 3 -in- 1 " femoral nerve block. Singelyn compared the efficacy of a continuous femoral nerve block performed before or after hip surgery in three groups of 15 patients (no block, block performed prior, or after surgery). Forty millilitres bupivacaine $0.25 \%$ with epinephrine mixed with $100 \mu \mathrm{g}$ fentanyl were injected followed by an infusion of bupivacaine $0.125 \%$ at $10 \mathrm{ml} \cdot \mathrm{hr}^{-1} .{ }^{10}$ This study was not double blind and peroperative effects are not reported. Postoperative analgesic morphine requirements, quantified by Patient Control Analgesia, were reduced in the groups with the continuous femoral nerve blocks when compared with the group without femoral block. The same author investigated, in 620 parients scheduled for hip, femoral shaft or knee surgery, the postoperative analgesic effects of a continuous femoral nerve block which was performed using $40 \mathrm{ml}$ bupivacaine $0.25 \%$ with epinephrine followed by a continuous infusion of bupivacaine $0.125 \%$ mixed with fentanyl and clonidine at a concentration of $1 \mu \mathrm{g} \cdot \mathrm{ml}^{-1}$ administered at a rate of $10 \mathrm{ml} \cdot \mathrm{hr}^{-1}$. He concluded that this technique was statistically less efficient for knee surgery than for hip and femoral shaft surgery. "Two flaws can be seen: 1) the absence of a control group; 2 ) the influence of the possible systemic effect of fentanyl or a mixture of fentanyl and clonidine on postoperative analgesia.

In conclusion, the " 3 -in-1" femoral nerve block offers a technically easy and safe method of providing pain relief in the early post-operative period. However, for longer term pain relief, a single shot technique femoral nerve block appears to be inadequate.

\section{References}

1 Winnie $A P$, Ramamurthy $S$, Durrani $Z$. The inguinal paravascular technic of lumbar plexus anesthesia: the “3-in-1 block." Anesth Analg 1973; 52: 989-96.

2 Tierney E, Lewis G, Hurtig JB, Johnson D. Femoral nerve block with bupivacaine 0.25 per cent for postoperative analgesia after open knee surgery. Can J Anaesth 1987; 5: 455-8. 
3 Edwards ND, Wright EM. Continuous low-dose 3-in-1 nerve blockade for postoperative pain relief after total knee replacement. Anesth Analg 1992; 75: 265-7.

4 Ringrose $N H$, Cross $M J$. Femoral nerve block in knee joint surgery. The American Journal of Sports Medicine 1984; 12: 398-402.

5 Davidas $J L$, Rondelet B, Besson L, Debouit JM, Banssillon $V$. Le bloc du nerf crural comme technique d'analgésie postopératoire en chirurgie du genou. Ann Fr Anesth Réanim 1986; 5: 483-5.

6 Schultz P, Anker-Moller E, Dabl JB, Christensen EF, Spangsberg N, Faunø P. Postoperative pain treatment after open knee surgery: continuous lumbar plexus block with bupivacaine versus epidural morphine. Reg Anesth 1991; 16: 34-7.

7 Patel NJ, Flasbburg MH, Paskin S, Grossman R. A regional anesthetic technique compared to general anesthesia for outpatient knee arthroscopy. Anesth Anaig 1986; 65: 185-7.

8 Tondare AS, Nadkarni AV. Femoral nerve block for fractured shaft of femur. Can Anaesth Soc J 1982; 29; 270-1.

9 Virenque Ch, Gaston JP. Bloc du nerf crural pour fracture de la diaphyse fémorale. Cahiers d'Anesthésiologie 1983; 31: 365-6.

10 Singelyn $F$, Vandewalle $F$, Gouverneur $J-M$. Effect of pre - vs postoperative continuous " 3 -in- 1 " block (CB)on postoperative pain after elective total hip replacement (THR). Anesthesiology 1993; 79: A900.

1.1 Singelyn FJ, Gouverneur JM. Continous "3-in-1" block (CB) as postoperative pain treatment after hip, femoral shaft or knee surgery: a large scale study of efficacy and side effects. Anesthesiology 1994; 81: Al054.

12 Parkinson SK, Mueller JB, Little WL, Bailey SL. Extent of blockade with various approaches to the lumbar plexus. Anesth Analg 1989; 68: 243-8.

13 Lang $S A, \Upsilon_{i p} R W$, Chang PC. The femoral "3-in-1" block revisited. J Clin Anesth 1993; 5 : 292-6.

14 Atannassoff $P G$, Weiss BM, Brull SJ, et al. Electromyographic comparison of obturator nerve block to three-in-one block. Anesth Analg 1995; 81: 529-33. 